\title{
Calibração de métodos de análise de fósforo e resposta do feijão ao fósforo no sulco ${ }^{(1)}$
}

\author{
Leo Nobre de Miranda(2), Juscelino Antonio de Azevedo(2), \\ Jeanne Christine Claessen de Miranda ${ }^{(2)}$ e Antonio Carlos Gomes ${ }^{(2)}$
}

\begin{abstract}
Resumo - O feijoeiro e o milho apresentam respostas significativas ao $\mathrm{P}$, mas deve-se avaliar adequadamente sua disponibilidade no solo para recomendar adubação fosfatada. O objetivo deste trabalho foi calibrar os métodos Mehlich-1, Mehlich-3 e Resina, pela relação entre teores de P extraídos do solo com produtividade das culturas de feijão e milho, e avaliar a resposta do feijoeiro à adubação fosfatada no sulco. Os tratamentos constituíram-se de 250, 500 e $1.000 \mathrm{~kg} \mathrm{ha}^{-1} \mathrm{de}_{2} \mathrm{O}_{5}$ aplicados a lanço, obtendose quatro cultivos de feijão 'Carioca' em rotação com milho 'BR 201'. No último cultivo do feijão, as

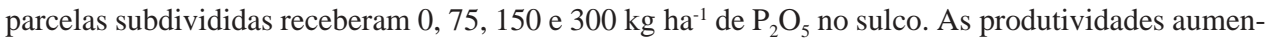
taram com a adubação fosfatada, sendo linear em relação ao feijão até $1.000 \mathrm{~kg} \mathrm{ha}^{-1} \mathrm{de}_{2} \mathrm{P}_{5}$, e quadrática em relação ao milho. Os três métodos apresentaram boa capacidade de predição da disponibilidade de $\mathrm{P}$ no solo, e mostraram correlação significativa entre si. O nível crítico de P para obter $80 \%$ do rendimento máximo para o milho foi de 10,14 e $17 \mathrm{mg} \mathrm{dm}^{-3}$, respectivamente, pelos métodos Mehlich-1, Mehlich-3 e Resina. $\mathrm{O}$ feijão apresentou resposta significativa à adubação fosfatada no sulco, variando com a disponibilidade de P existente no solo.
\end{abstract}

Termos para indexação: solo de cerrado, milho, rendimento de cultura, resina, troca iônica.

\section{Calibration of soil $\mathbf{P}$ methods and common bean response to phosphate fertilizer row application}

\begin{abstract}
The common bean and maize have presented significative responses to phosphate fertilizer, but it is necessary to evaluate the soil $\mathrm{P}$ availability to recommend $\mathrm{P}$ fertilization. The objective of this work was the calibration of Mehlich-1, Mehlich-3 and Ion-exchange Resin methods, through the relations between soil $\mathrm{P}$ availability and the crops grain yield, as well as the evaluation of the response of common bean to $\mathrm{P}$ row application. The treatments consisted of 250, 500 and $1.000 \mathrm{~kg} \mathrm{ha}^{-1} \mathrm{P}_{2} \mathrm{O}_{5}$ broadcasting, cultivating four crops of common bean 'Carioca' in rotation with maize 'BR 201'. For the last common bean crop, the splitted plots received 0, 75, 150 and $300 \mathrm{~kg} \mathrm{ha}^{-1} \mathrm{P}_{2} \mathrm{O}_{5}$ in row. The grain yield increased with phosphate levels, being linear for common bean up to $1.000 \mathrm{~kg} \mathrm{ha}^{-1} \mathrm{P}_{2} \mathrm{O}_{5}$, and quadratic for maize. The three methods presented a good capacity to predict the soil $\mathrm{P}$ availability, with significative correlation among themselves. The soil $\mathrm{P}$ critical level to obtain $80 \%$ of maximum grain yield for corn was 10,14 and $17 \mathrm{mg} \mathrm{dm}^{-3}$, respectively for Mehlich-1, Mehlich-3 and Resin methods. The common bean presented a significative response to phosphate fertilizer in row, which magnitude depended on the previous soil $\mathrm{P}$ availability.
\end{abstract}

Index terms: cerrado soils, maize, crop yield, resins, ion exchange.

\section{Introdução}

O feijoeiro e o milho cultivados em solos de cerrado têm apresentado respostas significativas ao $\mathrm{P}$

\footnotetext{
(1) Aceito para publicação em 21 de fevereiro de 2002 .

(2) Embrapa-Centro de Pesquisa Agropecuária dos Cerrados, Caixa Postal 08223, CEP 73301-970 Planaltina, DF E-mail: leo@cpac.embrapa.br, juscelin@cpac.embrapa.br, jeanne@cpac.embrapa.br, acarlos@cpac.embrapa.br
}

(Miranda et al., 1980; Silveira \& Moreira, 1990; Carvalho et al., 1995), porém é necessário avaliar adequadamente a sua disponibilidade no solo para que se possa recomendar a adubação fosfatada.

Existem vários métodos de avaliação da disponibilidade de $\mathrm{P}$ no solo, com princípios diferentes (Silva \& Raij, 1999). Entre eles, destaca-se o método de Mehlich-1 que é muito utilizado no Brasil e extrai a fração de $\mathrm{P}$ solúvel em ácido fraco e a fração trocável de K do solo. Esse método tem sido usado com fre- 
qüência na avaliação da disponibilidade de $\mathrm{P}$ em condições de campo, correlacionando-a com a produtividade de diversas culturas (Mielniczuk et al., 1971; Miranda \& Volkweiss, 1981; Lins et al.,1989). O método de Mehlich-3, de extração ácida, tem apresentado uma boa correlação entre os teores de P no solo com a resposta das plantas (Brasil \& Muraoka, 1997), além de extrair K, Ca, Mg, Mn e Zn (Tran et al., 1990). O método que utiliza as resinas trocadoras de íons, de uso bastante amplo, remove gradativamente e de forma contínua o P da solução do solo. Esse método, mediante uma mistura de resinas de troca aniônica e catiônica, permite também a extração de outros nutrientes, como Ca, Mg e K (Raij et al., 1986). Silva \& Raij (1996) e Büll et al. (1998) demonstraram boa capacidade desse método de predição da disponibilidade de $\mathrm{P}$ do solo para diversas culturas. Silva \& Raij (1999), em estudo comparativo de métodos, englobando a revisão de 72 trabalhos, concluíram que a resina trocadora de íons foi superior aos demais na correlação entre o $\mathrm{P}$ absorvido pelas plantas e o P extraído do solo.

Além de medir a disponibilidade de $\mathrm{P}$ no solo para recomendar a adubação fosfatada, é necessário avaliar a eficiência dessa adubação, de maneira a se obterem melhores produtividades das culturas, principalmente na região dos Cerrados, onde a deficiência de $\mathrm{P}$ é uma das principais limitações da fertilidade do solo (Goedert, 1983).

O objetivo deste trabalho foi comparar e calibrar os métodos Mehlich-1, Mehlich-3 e Resina, através da relação entre os teores de $\mathrm{P}$ extraídos do solo com a produtividade das culturas de feijão e milho, e avaliar a resposta do feijoeiro à adubação fosfatada no sulco.

\section{Material e Métodos}

O trabalho foi iniciado em 1990, na área experimental da Embrapa-Centro de Pesquisa Agropecuária dos Cerrados, Planaltina, DF, cultivando-se o feijão irrigado no período seco, em rotação com o milho no período chuvoso. Os tratamentos constituíram-se da combinação das doses de 250,500 e $1.000 \mathrm{~kg} \mathrm{ha}^{-1}$ de $\mathrm{P}_{2} \mathrm{O}_{5}$ aplicadas a lanço, como superfosfato triplo. Os detalhes experimentais estão mencionados em Miranda et al. (2000). Utilizou-se o delineamento de blocos ao acaso, em esquema fatorial, com três repetições. O experimento foi realizado em Latossolo
Vermelho-Escuro argiloso, cujas características iniciais são apresentadas na Tabela 1.

No período seco foi cultivado feijão, cultivar Carioca em níveis de irrigação adequado e restrito com densidade de 200.000 plantas ha $^{-1}$ e espaçamento entre linhas de $0,50 \mathrm{~m}$. No período chuvoso foi cultivado milho, cultivar BR 201, como cultura de rotação, com densidade de plantio de 50.000 plantas ha $^{-1}$ e espaçamento entre linhas de $1,00 \mathrm{~m}$. Antes de cada plantio foram coletadas 20 subamostras $(0-20 \mathrm{~cm})$ para formarem uma amostra composta por parcela, as quais foram submetidas à análise química, conforme Embrapa (1979). Os teores de P no solo antes do plantio das duas culturas foram extraídos pelos métodos de: Mehlich-1 ( $\mathrm{HCl} 0,05$ mol L-1 $+\mathrm{H}_{2} \mathrm{SO}_{4}$ $\left.0,0125 \mathrm{~mol} \mathrm{~L}^{-1}\right)$ Embrapa (1979), Mehlich-3 $\left(\mathrm{CH}_{3} \mathrm{COOH}\right.$ $0,2 \mathrm{~mol} \mathrm{~L}^{-1}+\mathrm{NH}_{4} \mathrm{NO}_{3} 0,25 \mathrm{~mol} \mathrm{~L}^{-1}+\mathrm{NH}_{4} \mathrm{~F} 0,015 \mathrm{~mol} \mathrm{~L}^{-1}+$ $\mathrm{HNO}_{3}$ 0,013 $\mathrm{mol} \mathrm{L}^{-1}+$ EDTA 0,001 mol L-1) Mehlich (1984) e, pelo método da Resina de Troca Aniônica (Raij et al., 1987). Foram realizadas amostragens de folhas do feijão e do milho no florescimento para análise química de macro e micronutrientes.

O trabalho de calibração de métodos de análise para P foi realizado a partir do segundo ano (1991/1992), após um cultivo de milho (1990/1991) e um de feijão (1991), num total de quatro cultivos de cada cultura até o ano de 1995. Foram considerados os dados de produtividade das duas culturas e os teores de $\mathrm{P}$ no solo e na planta, nos três níveis de adubação fosfatada. Na cultura do feijão, consideraram-se somente as parcelas com irrigação adequada, descrita em Miranda et al. (2000). A produção de grãos de cada cultura foi ajustada para $13 \%$ de umidade, e, considerando-se a produção máxima de cada ano como $100 \%$, foram calculados os rendimentos relativos em porcentual. Os dados foram submetidos à análise de regressão e correlação pelos procedimentos do SAS (SAS Institute, 1989). Foram testadas as relações entre os rendimentos relativos do feijão e do milho com os teores de P no solo, extraídos pelos três métodos, para determinação dos níveis críticos de P no solo, bem como com os teores de P na planta.

No último cultivo do feijão no período seco de 1995, o experimento foi reformulado para se estudar, também, a resposta do feijão à adubação fosfatada no sulco de plantio, como parte dos estudos de calibração de métodos de análise de solo com relação ao $\mathrm{P}$, para essa cultura. As parcelas foram subdivididas, e, para cada nível de disponibilidade de $\mathrm{P}$ no solo decorrentes das doses iniciais de $\mathrm{P}_{2} \mathrm{O}_{5}$ a lanço, foram aplicados $0,75,150$ e $300 \mathrm{~kg} \mathrm{ha}^{-1} \mathrm{de}$ $\mathrm{P}_{2} \mathrm{O}_{5}$ no sulco de semeadura. $\mathrm{A}$ área foi irrigada por aspersão, sempre que a tensão de água no solo à profundidade de $10 \mathrm{~cm}$ atingia $40 \mathrm{kPa}$. Utilizaram-se $582 \mathrm{~mm}$ de água durante todo o ciclo, sendo que $41,3 \%$ foram aplicados no 
período mais crítico do início da floração ao desenvolvimento de vagens, dos 30 aos 69 dias após a emergência. Aplicaram-se $80 \mathrm{~kg} \mathrm{ha}^{-1}$ de $\mathrm{N}$ (uréia), sendo $1 / 3$ no plantio, 1/3 em cobertura aos 20 dias e 1/3 aos 35 dias após a germinação. As sementes foram infectadas com Rhizobium leguminosarum bv. phaseoli, antes do plantio, com a dose de $1 \mathrm{~kg}$ de inoculante por $40 \mathrm{~kg}$ de sementes. O milho recebeu, anualmente, $120 \mathrm{~kg} \mathrm{ha}^{-1}$ de $\mathrm{N}$ (uréia), sendo $1 / 3$ no plantio, 1/3 em cobertura aos 35 dias e 1/3 aos 45 dias após a germinação. Nas duas culturas foram aplicados também, a cada cultivo, $60 \mathrm{~kg} \mathrm{ha}^{-1}$ de $\mathrm{K}_{2} \mathrm{O}$ (cloreto de potássio). Os dados de produção de grãos, ajustados para $13 \%$ de umidade, foram submetidos à análise de variância, e as médias, comparadas pelo teste de Duncan a 5\% de probabilidade (SAS Institute, 1989).

\section{Resultados e Discussão}

No período entre 1991 e 1995 as condições do solo estavam adequadas para o cultivo do feijão e do milho, independentemente dos níveis de aduba- ção fosfatada (Tabela 1). O pH estava acima de 5,5, com teores insignificantes de $\mathrm{Al}$ trocável, teores adequados de $\mathrm{Ca}, \mathrm{Mg}$ e $\mathrm{K}$ trocáveis e saturação por bases do solo acima de $40 \%$.

As duas culturas mostraram boas produtividades, e pode-se observar a manutenção do efeito residual da adubação fosfatada aplicada a lanço no início, através dos cultivos sucessivos de milho e feijão (Tabela 2). O feijão mostrou um decréscimo de produtividade maior que o milho com o tempo de cultivo.

Os teores de P nas folhas do milho e feijão aumentaram com as doses de adubação fosfatada, e mesmo no nível mais baixo de $\mathrm{P}$ estavam, nos dois primeiros cultivos, acima dos níveis críticos de 2,2 $\mathrm{g} \mathrm{kg}^{-1}$ e 3,0 $\mathrm{g} \mathrm{kg}^{-1}$, respectivamente, no milho e no feijão (Raij, 1991). Com o tempo de cultivo, os teores de P nas folhas foi diminuindo nas duas doses mais baixas de adubação fosfatada, chegando a valores abaixo dos níveis críticos nos dois últimos cultivos (Tabela 2).

Tabela 1. Características químicas do Latossolo Vermelho-Escuro argiloso em 1990 (no início do experimento), antes do segundo plantio de milho em 1991 e antes do quinto plantio de feijão em 1995.

\begin{tabular}{lccc}
\hline Características do solo & Março/ $1990^{(1)}$ & Outubro/1991 & Março/1995 \\
\hline $\mathrm{pH} \mathrm{em} \mathrm{água}(1: 2,5)$ & 5,30 & 6,20 & 5,70 \\
$\mathrm{Al}^{3+}\left(\mathrm{cmol}_{\mathrm{c}} \mathrm{dm}^{-3}\right)$ & 0,85 & 0,02 & 0,14 \\
$\mathrm{Ca}^{2+}+\mathrm{Mg}^{2+}\left(\mathrm{cmol}_{\mathrm{c}} \mathrm{dm}^{-3}\right)$ & 0,70 & 3,60 & 3,53 \\
$\mathrm{~K}^{+}\left(\mathrm{cmol}_{\mathrm{c}} \mathrm{dm}^{-3}\right)$ & 0,03 & 0,26 & 0,24 \\
$\mathrm{H}^{2+}+\mathrm{Al}^{3+}\left(\mathrm{cmol}_{\mathrm{c}} \mathrm{dm}^{-3}\right)$ & 6,81 & 3,89 & 5,27 \\
Saturação por bases $(\%)_{\mathrm{C}\left(\mathrm{g} \mathrm{dm}^{-3}\right)}$ & 9,70 & 49,80 & 41,70 \\
\hline
\end{tabular}

(1) Outras características iniciais: $1,10 \mathrm{~g} \mathrm{dm}^{-3}$ de P; $530 \mathrm{~g} \mathrm{dm}^{-3}$ de argila; $70 \mathrm{~g} \mathrm{dm}^{-3}$ de silte e $400 \mathrm{~g} \mathrm{dm}^{-3}$ de areia. (2) Dados médios de todas as parcelas dos tratamentos de adubação fosfatada.

Tabela 2. Produtividade de grãos e teores de fósforo nas folhas de milho (M) e feijão (F) irrigado, em razão de doses de $\mathrm{P}_{2} \mathrm{O}_{5}$ aplicadas a lanço antes do primeiro plantio em 1990, em Latossolo Vermelho-Escuro argiloso ${ }^{(1)}$.

\begin{tabular}{cccccccrr}
\hline $\mathrm{P}_{2} \mathrm{O}_{5}-90 / 91$ & $\mathrm{M}-91 / 92$ & $\mathrm{~F}-92^{(2)}$ & $\mathrm{M}-92 / 93$ & $\mathrm{~F}-93^{(2)}$ & $\mathrm{M}-93 / 94$ & $\mathrm{~F}-94^{(2)}$ & $\mathrm{M}-94 / 95$ & $\mathrm{~F}-95^{(3)}$ \\
\hline $\left.\mathrm{kg} \mathrm{ha}^{-1}\right)$ & & \multicolumn{7}{c}{ Produtividade de grãos $\left(\mathrm{kg} \mathrm{ha}^{-1}\right)$} \\
250 & $5.164 \mathrm{c}$ & $1.060 \mathrm{~d}$ & $5.475 \mathrm{e}$ & $920 \mathrm{e}$ & $3.616 \mathrm{c}$ & $237 \mathrm{e}$ & $1.954 \mathrm{c}$ & $62 \mathrm{e}$ \\
500 & $6.258 \mathrm{~b}$ & $1.887 \mathrm{c}$ & $7.519 \mathrm{~b}$ & $1.946 \mathrm{c}$ & $6.257 \mathrm{~b}$ & $812 \mathrm{c}$ & $4.047 \mathrm{~b}$ & $202 \mathrm{e}$ \\
1.000 & $7.265 \mathrm{a}$ & $3.085 \mathrm{a}$ & $8.767 \mathrm{a}$ & $3.718 \mathrm{a}$ & $8.961 \mathrm{a}$ & $2.211 \mathrm{a}$ & $6.746 \mathrm{a}$ & $1.177 \mathrm{~d}$ \\
\hline \multicolumn{7}{c}{} & & \multicolumn{7}{c}{ Fósforo na folha $\left(\mathrm{g} \mathrm{kg}^{-1}\right)$} \\
250 & 3,2 & 2,5 & 2,0 & 2,8 & 2,1 & 2,7 & 2,2 & 1,7 \\
500 & 3,5 & 3,1 & 2,5 & 3,2 & 2,8 & 3,0 & 2,6 & 1,9 \\
1.000 & 3,7 & 4,0 & 3,0 & 4,6 & 3,2 & 3,5 & 3,2 & 2,2 \\
\hline
\end{tabular}

(1) Valores seguidos da mesma letra, na coluna, não diferem entre si pelo teste de Tukey a 5\% de probabilidade; os dados representam médias de seis (milho) e três (feijão) repetições. ${ }^{(2)}$ Médias classificadas pela análise estatística incluindo os tratamentos com irrigação restrita apresentada em Miranda et al. (2000). ${ }^{(3)}$ Médias classificadas pelo dms $5 \%$ da interação entre $\mathrm{P}_{2} \mathrm{O}_{5}$ no sulco e $\mathrm{P}_{2} \mathrm{O}_{5}$ a lanço. 
Os teores de P no solo antes de cada plantio, extraídos pelos três métodos, mostram um decréscimo gradativo com o tempo de cultivo (Tabela 3). Pelas equações de regressão em cada dose de adubação fosfatada, com o tempo de cultivo, observa-se que esse decréscimo foi relativamente maior, à medida que se aumentou a dose de fósforo. Resultados semelhantes foram obtidos por Lins et al. (1989), em solos de cerrado. O método da Resina de Troca Aniônica extraiu mais P que o Mehlich-3, e este, mais que o Mehlich-1, o qual tem apresentado baixa capacidade de extração em solos argilosos (Raij et al., 1986). Os métodos apresentaram correlação significativa entre si (coeficientes de correlação entre $0,97 * *$ e $0,99 * *)$; isto indica que, embora extraiam quantidades diferentes de $\mathrm{P}$, guardam a mesma proporção e variabilidade semelhante, nas amostras com diferentes teores desse nutriente. A variação dos teores de P no solo e nas folhas também apresentou correlação significativa e semelhante nos três métodos de análise de solo, o que indica a sensibilidade desses métodos na avaliação dos teores de $\mathrm{P}$ disponíveis no solo e de sua absorção pelas duas culturas.

A relação entre o rendimento relativo (porcentual da produção máxima de cada cultivo) do feijão irrigado e do milho com os teores de P no solo, pelos três métodos de extração de $\mathrm{P}$, foi linear em relação ao feijão irrigado, e quadrática quanto ao milho de sequeiro, que apresentou produtividade máxima em resposta aos níveis de disponibilidade de P no solo (Figura 1). Esses dados mostram uma resposta significativa do feijão a altas doses de adubação fosfatada aplicadas a lanço antes do plantio, e, por outro lado, indicam que a calibração de métodos de análise de $\mathrm{P}$ com esta cultura não pode ser feita pelo modo tradicional, como se faz com outras culturas anuais. Em face do sistema radicular pouco desenvolvido (Inforzato \& Myasaka, 1963; Rosolem, 1987), o feijão explora um pequeno volume de solo e promove um menor aproveitamento do $\mathrm{P}$ disponível em toda a camada arável, e não maximiza a produtividade, mesmo quando se aplicaram altas doses de $\mathrm{P}$ a lanço. Conseqüentemente, não se pode definir o nível crítico de $\mathrm{P}$ no solo que está em torno de $80 \%$ do rendimento máximo em culturas como o milho (Miranda et al., 1980). É provável que a utilização de doses ainda maiores de $\mathrm{P}$ a lanço permita a obtenção de produtividades máximas do feijão. Berger et al. (1982) e Silveira \& Moreira (1990) sugerem que, para o feijoeiro, a adubação fosfatada é mais eficiente, se aplicada de forma concentrada no sulco de plantio.

Quanto ao milho, o nível crítico pelo método de Mehlich-1 para se obter $80 \%$ do rendimento relativo, está em torno de $10 \mathrm{mg} \mathrm{dm}^{-3}$ de P (Figura 2), semelhante ao sugerido por Goedert et al. (1985) para solos de cerrado. Em relação aos outros métodos de extração, o nível crítico de $\mathrm{P}$ no solo para o milho foi de $14 \mathrm{mg} \mathrm{dm}^{-3}$ de $\mathrm{P}$ e $17 \mathrm{mg} \mathrm{dm}^{-3}$ de P, respectiva-

Tabela 3. Teores de fósforo (P) no solo extraído pelos métodos de Mehlich-1, Mehlich-3 e Resina de Troca Aniônica antes dos plantios de milho (M) e de feijão irrigado (F), em razão de doses de $\mathrm{P}_{2} \mathrm{O}_{5}$ aplicadas a lanço antes do primeiro plantio em 1990, em Latossolo Vermelho-Escuro argiloso e suas equações de regressão e coeficientes de determinação. Médias de três repetições.

\begin{tabular}{|c|c|c|c|c|c|c|c|c|c|c|}
\hline \multirow{2}{*}{$\begin{array}{c}\mathrm{P}_{2} \mathrm{O}_{5}\left(\mathrm{~kg} \mathrm{ha}^{-1}\right) \\
1990 / 91\end{array}$} & \multicolumn{8}{|c|}{ P no solo $\left(\mathrm{mg} \mathrm{dm}^{-3}\right)$} & \multirow[t]{2}{*}{ Regressão } & \multirow[t]{2}{*}{$\mathrm{R}^{2}$} \\
\hline & M - 91/92 & $F-92$ & M - 92/93 & $F-93$ & M - 93/94 & $\mathrm{F}-94$ & M - 94/95 & $F-95$ & & \\
\hline \multicolumn{11}{|c|}{ Mehlich-1 } \\
\hline 250 & 5,3 & 4,3 & 3,5 & 2,9 & 2,5 & 2,2 & 2,2 & 2,0 & $Y=5,14-0,45 X$ & $0,88 * *$ \\
\hline 500 & 12,4 & 10,7 & 7,8 & 6,8 & 6,2 & 5,2 & 4,9 & 3,9 & $Y=12,43-1,15 X$ & $0,92 * *$ \\
\hline 1.000 & 36,6 & 26,1 & 20,1 & 17,7 & 16,5 & 14,0 & 13,7 & 9,4 & $Y=33,90-3,26 X$ & $0,86 * *$ \\
\hline \multicolumn{11}{|c|}{ Mehlich-3 } \\
\hline 250 & 10,6 & 8,0 & 7,2 & 4,3 & 3,7 & 3,5 & 3,4 & 3,4 & $Y=10,07-1,01 X$ & $0,82 * *$ \\
\hline 500 & 22,9 & 16,7 & 11,6 & 8,9 & 8,0 & 7,2 & 6,8 & 5,9 & $Y=20,78-2,17 X$ & $0,81 * *$ \\
\hline 1.000 & 45,3 & 29,4 & 25,5 & 21,6 & 20,2 & 18,0 & 15,5 & 13,2 & $Y=40,63-3,79 X$ & $0,83 * *$ \\
\hline \multicolumn{11}{|c|}{ Resina de Troca Aniônica } \\
\hline 250 & 13,6 & 9,3 & 7,0 & 5,5 & 5,4 & 4,8 & 4,5 & 3,9 & $Y=12,03-1,17 X$ & $0,78 * *$ \\
\hline 500 & 32,3 & 18,0 & 12,4 & 11,8 & 10,9 & 8,9 & 8,1 & 7,0 & $Y=26,42-2,83 X$ & $0,71 * *$ \\
\hline 1.000 & 61,0 & 41,1 & 34,0 & 23,5 & 21,9 & 20,6 & 18,5 & 16,2 & $Y=54,69-5,58 X$ & $0,81^{* *}$ \\
\hline
\end{tabular}


mente, em relação aos métodos de Mehlich-3 e Resina. Grande et al. (1986) constataram maior capacidade de extração de $\mathrm{P}$ pelo método da Resina em relação ao Mehlich-1, sendo que a Resina trocadora de
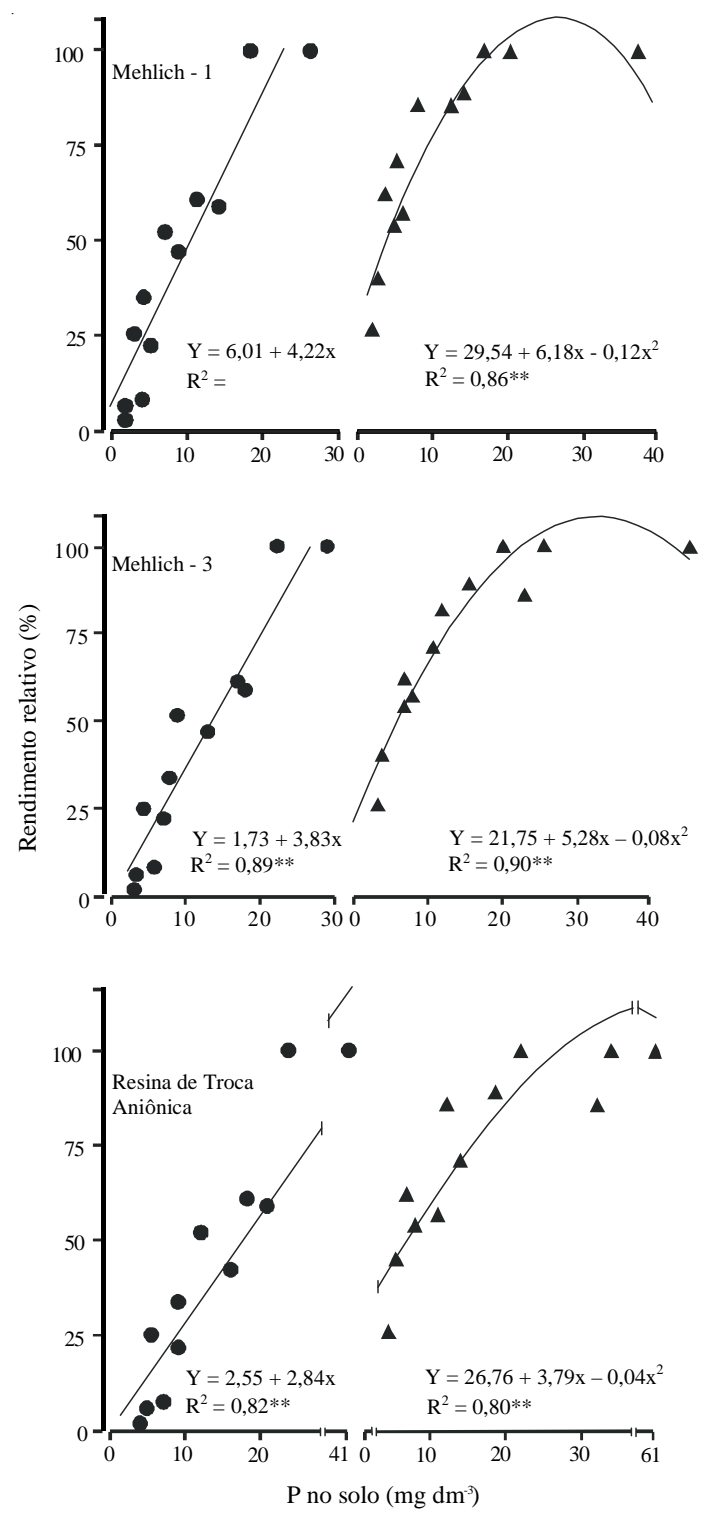

Figura 1. Relação entre o rendimento relativo (porcentual da produção máxima de cada cultivo) de quatro cultivos de

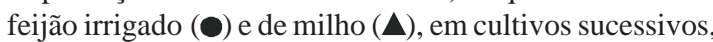
e os teores de P no solo antes do plantio, extraídos pelos métodos de Mehlich-1, Mehlich-3 e Resina de Troca Aniônica. íons foi o extrator mais adequado para avaliar a disponibilidade de $\mathrm{P}$ para o arroz irrigado.

Os três métodos apresentam boa capacidade de predição da disponibilidade de P no solo, e guardam boa correlação entre si. Então, a escolha quanto à utilização de um deles para análise do solo vai depender de sua praticidade de execução no laboratório. Como as quantidades de $\mathrm{P}$ extraídas são diferentes em relação a cada método, os níveis críticos tomados como base para recomendação da adubação fosfatada também serão diferentes.

No período seco de 1995, aplicaram-se doses de adubação fosfatada no sulco de plantio do feijoeiro, nas parcelas com os três níveis diferentes de disponibilidade de $\mathrm{P}$ criados a partir das aplicações iniciais do adubo fosfatado a lanço. Houve resposta significativa do feijoeiro à adubação fosfatada no sulco de plantio, cuja magnitude variou de acordo com o nível de disponibilidade de $\mathrm{P}$ já existente no solo antes do plantio. Considerando-se apenas os efeitos da adubação fosfatada no sulco de semeadura, a produtividade média do feijão aumentou até a dose de $150 \mathrm{~kg} \mathrm{ha}^{-1}$ de $\mathrm{P}_{2} \mathrm{O}_{5}$. Esta resposta foi também crescente com a disponibilidade de $\mathrm{P}$ no solo, decorrente das adubações iniciais a lanço, independentemente da adubação no sulco, e foi maior no solo com dose inicial de $1.000 \mathrm{~kg} \mathrm{ha}^{-1} \mathrm{de}_{2} \mathrm{O}_{5}$ a lanço. Nas parcelas com aplicação inicial de $250 \mathrm{~kg} \mathrm{ha}^{-1}$ de

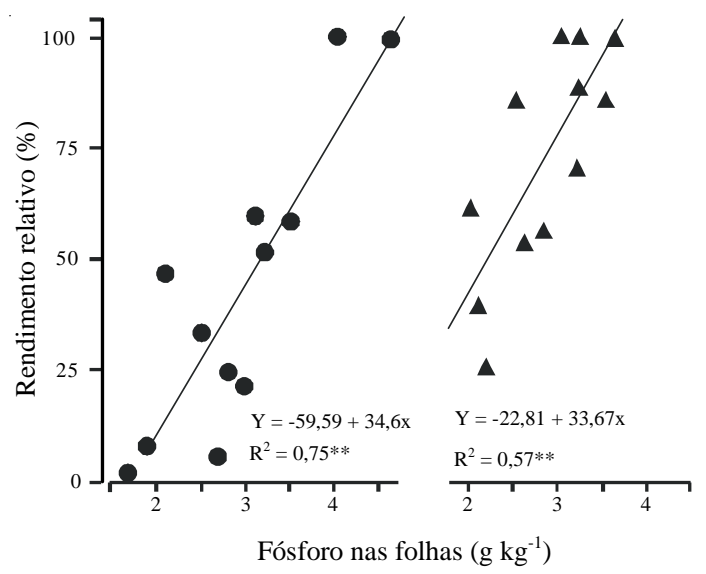

Figura 2. Relação entre o rendimento relativo (porcentual da produção máxima de cada cultivo) de quatro cultivos de feijão irrigado $(\mathbf{)})$ e de milho $(\boldsymbol{\Delta})$, em cultivos sucessivos, e os teores de $\mathrm{P}$ nas folhas. 
$\mathrm{P}_{2} \mathrm{O}_{5}$, a produtividade máxima foi de $2.500 \mathrm{~kg} \mathrm{ha}^{-1}$, quando se utilizou a dose de $300 \mathrm{~kg} \mathrm{ha}^{-1} \mathrm{de}_{2} \mathrm{O}_{5}$ no sulco. Essa mesma produtividade foi obtida com as doses de 150 e $75 \mathrm{~kg} \mathrm{ha}^{-1}$ de $\mathrm{P}_{2} \mathrm{O}_{5}$ no sulco, respectivamente, no solo com doses iniciais de 500 e $1.000 \mathrm{~kg} \mathrm{ha}^{-1}$ de $\mathrm{P}_{2} \mathrm{O}_{5}$ a lanço. Barbosa Filho \& Silva (1994) também obtiveram tetos máximos de produtividade para o feijão, com aplicações de doses de adubação fosfatada semelhantes no sulco de plantio.

Conforme o acima mencionado, a produtividade máxima do feijão não foi atingida, mesmo com altas doses de adubação fosfatada a lanço. Entretanto, pela combinação com doses de $\mathrm{P}$ no sulco de plantio foram alcançados tetos máximos de produtividade dessa cultura, e a resposta do feijoeiro à adubação fosfatada no sulco foi quadrática (Figura 3). Pelas equações obtidas em cada nível de P, para se obter $80 \%$ do rendimento máximo, seria necessário aplicar 69, 116 e $195 \mathrm{~kg} \mathrm{ha}^{-1}$ de $\mathrm{P}_{2} \mathrm{O}_{5}$, respectivamente, em solos com disponibilidade de $\mathrm{P}$ pelo método de Mehlich-1, de 9,4, 3,9 e 2,0 mg dm${ }^{-3}$ de P (Tabela 3). Com base nesses resultados, pode-se recomendar adubação fosfatada no feijão, de modo semelhante

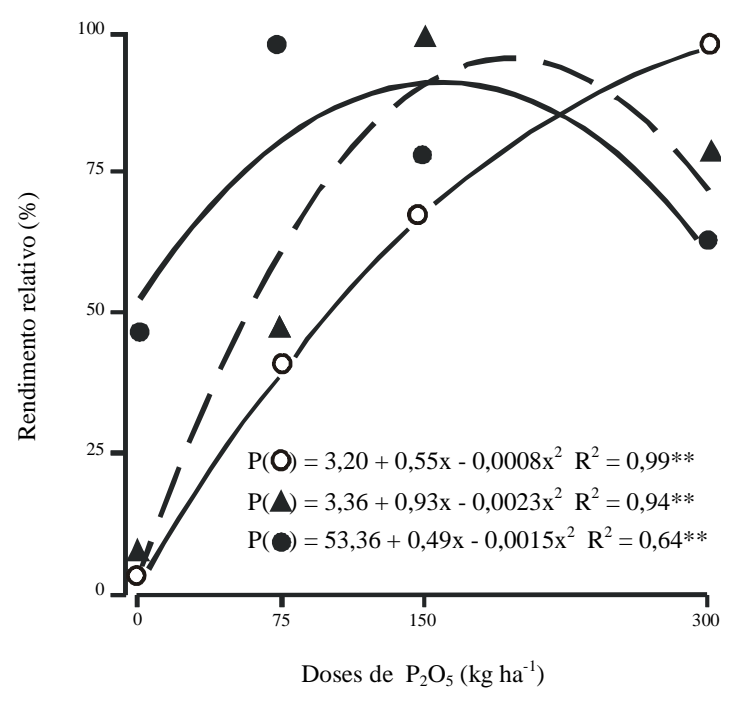

Figura 3. Relação entre o rendimento relativo (porcentual da produção máxima de cada cultivo) de feijão cultivar Carioca, e doses de $\mathrm{P}_{2} \mathrm{O}_{5}$ no sulco de plantio em 1995, em Latossolo Vermelho-Escuro argiloso que tinha recebido as doses $250(\mathbf{O}) ; 500(\mathbf{\Delta})$ e $1.000(\mathbf{O}) \mathrm{kg} \mathrm{ha}^{-1} \mathrm{de}_{2} \mathrm{O}_{5}$ a lanço em 1990. Dados médios de três repetições. ao efetuado na cultura do milho, para a qual se considera o nível crítico de 10 ppm de P no solo pelo método de Mehlich-1 (Goedert et al., 1985), com adubação de manutenção, também semelhante, de 70 a $80 \mathrm{~kg} \mathrm{ha}^{-1}$ de $\mathrm{P}_{2} \mathrm{O}_{5}$ no sulco de plantio (Miranda et al., 1980).

\section{Conclusões}

1. Os métodos de Mehlich-1, Mehlich-3 e Resina apresentam boa capacidade de predição da disponibilidade de fósforo no solo para o milho e o feijão.

2. O método da Resina extrai mais fósforo que o Mehlich-3, e este, mais que o Mehlich-1; estes três métodos apresentam correlação significativa entre si.

3. O nível crítico de P nesse solo para se obter $80 \%$ do rendimento relativo, no caso do milho, é de 10,14 e $17 \mathrm{mg} \mathrm{dm}^{-3}$ de $\mathrm{P}$, respectivamente, em relação aos métodos de Mehlich-1, Mehlich-3 e Resina.

4. A produtividade de grãos do feijão e do milho aumenta com os níveis de adubação fosfatada a lanço, sendo que no caso do feijão essa resposta é linear até a dose de $1.000 \mathrm{~kg} \mathrm{ha}^{-1}$ de $\mathrm{P}_{2} \mathrm{O}_{5}$.

5. Não se pode definir o nível crítico de $\mathrm{P}$ para a cultura do feijão, em razão da adubação fosfatada a lanço até a dose de $1.000 \mathrm{~kg} \mathrm{ha}^{-1}$ de $\mathrm{P}_{2} \mathrm{O}_{5}$.

6. O feijão apresenta resposta significativa à adubação fosfatada no sulco de plantio, que varia de acordo com o nível de disponibilidade de $\mathrm{P}$ existente no solo.

\section{Referências}

BARBOSA FILHO, M. P.; SILVA, O. F. da. Aspectos agro-econômicos da calagem e da adubação nas culturas de arroz e feijão irrigados por aspersão. Pesquisa Agropecuária Brasileira, Brasília, v. 29, n. 11, p. 16571667, nov. 1994.

BERGER, P. G.; VIEIRA, C.; CHAGAS, J. M.; CARDOSO, A. A. Resposta do feijoeiro (Phaseolus vulgaris L.) à adubação nitrogenada e fosfatada. In: REUNIÃO NACIONAL DE PESQUISA DE FEIJÃO, 1., 1982, Goiânia. Anais... Goiânia: Embrapa-CNPAF, 1982. p. $178-181$.

BRASIL, E. C.; MURAOKA, T. Extratores de fósforo em solos da Amazônia tratados com fertilizantes fosfatados. Revista Brasileira de Ciência do Solo, Campinas, v. 21, n. 4, p. 599-606, 1997. 
BÜLL, L. T.; FORLI, F.; TECCHIO, M. A.; CORRÊA, J. C. Relações entre fósforo extraído por resina e respostas da cultura do alho vernalizado à adubação fosfatada em cinco solos com e sem adubação orgânica. Revista Brasileira de Ciência do Solo, Campinas, v. 22, n. 3, p. 459470, 1998.

CARVALHO, A. A. de; FAGERIA, N. K.; OLIVEIRA, I. P. de; KINJO, T. Resposta do feijoeiro à aplicação de fósforo em solos dos cerrados. Revista Brasileira de Ciência do Solo, Campinas, v. 19, n. 1, p. 61-67, 1995.

EMBRAPA. Serviço Nacional de Levantamento de Solos (Rio de Janeiro, RJ). Manual de métodos de análises de solo. Rio de Janeiro, 1979. Não paginado.

GOEDERT, W. J. Management of the Cerrado soils of Brazil: a review. Journal of Soil Science, Oxford, v. 34, n. 3, p. 405-428, 1983.

GOEDERT, W. J.; SOUSA, D. M. G.; LOBATO, E. Fósforo. In: GOEDERT, W. J. (Ed.). Solos dos cerrados: tecnologias e estratégias de manejo. São Paulo: Nobel/ Embrapa-CPAC, 1985. p. 129-166.

GRANDE, M. A.; CURI, N.; QUAGGIO, J. A. Disponibilidade de fósforo pelos extratores de Mehlich e resina, em solos cultivados com arroz irrigado. Revista Brasileira de Ciência do Solo, Campinas, v. 10, n. 1, p. 45-50, 1986.

INFORZATO, R.; MYASAKA, S. Sistema radicular do feijoeiro em dois solos do Estado de São Paulo. Bragantia, Campinas, v. 22, n. 2, p. 477-482, 1963.

LINS, I. D. G.; COX, F. R.; SOUSA, D. M. G. Teste de um modelo matemático para otimizar a adubação fosfatada na cultura da soja em solos sob cerrado com diferentes teores e tipos de argila. Revista Brasileira de Ciência do Solo, Campinas, v. 13, n. 1, p. 65-73, 1989.

MEHLICH, A. Mehlich-3 soil test extractant: a modification of Mehlich-2 extractant. Communications in Soil Science and Plant Analysis, New York, v. 15, n. 12, p. 1409-1416, 1984.

MIELNICZUK, J.; LUDWICK, A. E.; VOLKWEISS, S. J.; PATELLA, J. F.; MACHADO, M. O. Estudos de calibração de análises para fósforo e potássio do solo com a cultura do trigo. In: CONGRESSO BRASILEIRO DE CIÊNCIA DO SOLO, 12., Curitiba, 1969. Anais... Rio de Janeiro: Equipe de Pedologia e Fertilidade do Solo, 1971. p. 53-63.

MIRANDA, L. N. de; AZEVEDO, J. A. de; MIRANDA, J. C. C. de; GOMES, A. C. Produtividade do feijoeiro em resposta à adubação fosfatada e regimes de irrigação em solo de cerrado. Pesquisa Agropecuária Brasileira, Brasília, v. 35, n. 4, p. 703-710, abr. 2000.

MIRANDA, L. N. de; MIELNICZUK, J.; LOBATO, E. Calagem e adubação corretiva. In:. SIMPÓSIO SOBRE O CERRADO, 5., 1979, Brasília. Anais... Brasília: Editerra, 1980. p. 523-578.

MIRANDA, L. N. de; VOLKWEISS, S. J. Relações entre a resposta da soja à adubação fosfatada e alguns parâmetros do solo. Revista Brasileira de Ciência do Solo, Campinas, v. 5, n. 1, p. 58-63, 1981.

RAIJ, B. van. Fertilidade do solo e adubação. Piracicaba: Ceres/Potafos, 1991. 343 p.

RAIJ, B. van; QUAGGIO, J. A.; CANTARELLA, H.; FERREIRA, M. E.; LOPES, A. S.; BATAGLIA, O. Análise química do solo para fins de fertilidade. Campinas: Fundação Cargill, 1987. 170 p.

RAIJ, B. van; QUAGGIO, J. A.; SILVA, N. M. da. Extraction of phosphorus, potassium, calcium, and magnesium from soils by ion-exchange resin procedure. Communications in Soil Science and Plant Analysis, New York, v. 17, n. 5, p. 547-566, 1986.

ROSOLEM, C. A. Nutrição e adubação do feijoeiro. Piracicaba: Associação Brasileira para Pesquisa da Potassa e Fosfato, 1987. 93 p. (Boletim Técnico, 1).

SAS INSTITUTE (Cary, Estados Unidos). Statistical analysis systems user's guide: version 6 . 4. ed. Cary, 1989. v. 1.

SILVA, F. C. da; RAIJ, B. van. Avaliação da disponibilidade de fósforo por diversos extratores, em amostras de solos cultivados com cana-de-açúcar. Revista Brasileira de Ciência do Solo, Campinas, v. 20, n. 1, p. 83-90, 1996.

SILVA, F. C. da; RAIJ, B. van. Disponibilidade de fósforo em solos avaliada por diferentes extratores. Pesquisa Agropecuária Brasileira, Brasília, v. 34, n. 2, p. 267-288, fev. 1999.

SILVEIRA, P. M. da; MOREIRA, J. A. A. Resposta do feijoeiro a doses de fósforo e lâminas de água de irrigação. Revista Brasileira de Ciência do Solo, Campinas, v. 14, n. 1, p. 63-67, 1990.

TRAN, T. S.; GIROUX, M.; GUILBEAUT, J.; AUDESS, P. Evaluation of Mehlich-III extractant to estimate the available $\mathrm{P}$ in Quebec soils. Communications in Soil Science and Plant Analysis, New York, v. 21, n. 1/2, p. 1-28, 1990. 